\title{
Statin intolerance - still more questions than answers
}

\section{- Iveta Merćep*, (DLukrecija Anzić², (D)Ema Budimir ${ }^{2}$}

'University of Zagreb School of Medicine, University Hospital Centre Zagreb, Zagreb, Croatia

2University of Zagreb School of Medicine, Zagreb, Croatia
RECEIVED:

February 19, 2020

ACCEPTED:

February 22, 2020
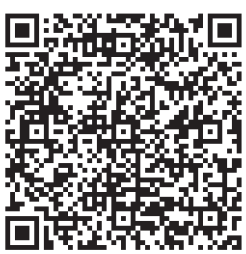

$\square$ Cardiologia Croatica 2020;15(3-4):58.
KEYWORDS: statins, intolerance, adverse effects.

CITATION: Cardiol Croat. 2020;15(3-4):58. | https://doi.org/10.15836/ccar2020.58

*ADDRESS FOR CORRESPONDENCE: Iveta Merćep, KBC Zagreb, Kišpatićeva 12, HR-10000 Zagreb, Croatia. / Phone: +385-91-25-00-599 / E-mail: imercep@gmail.com

ORCID: Iveta Merćep, https://orcid.org/0000-0003-2824-9222 • Lukrecija Anzić, https://orcid.org/0000-0002-2949-8733 Ema Budimir, https://orcid.org/0000-0001-7937-7019

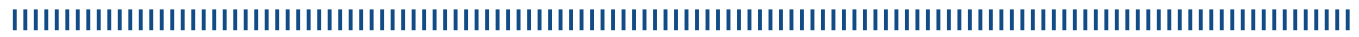

Statins reduce cardiovascular mortality and morbidity as well as cardiovascular events in patients with a very high risk of cardiovascular disease and also in subjects with a moderate or high risk by reducing the levels of low-density lipoprotein cholesterol.

Although statins are considered to be drugs with a very good safety profile, their wide use seems to evoke concerns about the compromising adverse effects overpowering proven beneficial ones.

Patients frequently discontinue statin therapy without medical advice due to unfavorable events, thereby substantially increasing their risk of cardiovascular events. Statin discontinuation is a great problem and appears to be growing.

Complete statin intolerance is relatively rare. Step-by-step approach that includes careful examination of all possible statin-intolerance-increasing factors would help patients to continue statin therapy even if experiencing statin-associated side effects. 